\title{
Knowledge of HIV and VCT and attitude to VCT among National Youth Service Corps members in Ilesa and Ife, South Western Nigeria.
}

\author{
*Eyitope O. Amu ${ }^{1}$, Foluke A. Olatona ${ }^{2}$ \\ ${ }^{*}$ (Department of Community Medicine, Ekiti State University Teaching Hospital, Ado-Ekiti, Nigeria) \\ ${ }_{2}^{2}$ (Department of Community Health, Lagos University Teaching Hospital, Lagos, Nigeria)
}

\begin{abstract}
The study assessed knowledge about Human Immunodeficiency Virus (HIV) and Voluntary Counselling and Testing (VCT) and attitude to VCT among National Youth Service Corps (NYSC) members in Ilesa and Ile-Ife, South-Western, Nigeria. The study employed a cross-sectional descriptive design. A pre-tested, self-administered, semi-structured questionnaire was used to elicit information from 330 NYSC members who were recruited by multi-stage sampling method from Ilesa and Ile-Ife Local Government Areas, Osun State, Nigeria. The data was analysed using SPSS version 15. The results showed that over $75 \%$ of the respondents knew the common modes of HIV transmission and prevention, the meaning of VCT and also had good attitude to some aspects of VCT. However, most of them equally had misconceptions about HIV and VCT. On the whole, only 19.5 and $20.5 \%$ of the respondents had good knowledge of HIV and VCT respectively while the rest had fair and poor knowledge. Fifty eight percent had positive attitude to VCT while $42.0 \%$ had negative attitude. The study concluded that the respondents had a fair knowledge of HIV and VCT and a positive attitude to VCT. Educational programs on HIV and VCT, targeted at correcting misconceptions should be intensified among corps members.
\end{abstract}

Keywords: Attitude to VCT, HIV knowledge, national youth service corps, Southwestern Nigeria, VCT knowledge

\section{Introduction}

The Human Immunodeficiency Virus/Acquired Immunodeficiency Syndrome remains a major public health problem. Though the disease was first diagnosed about thirty-two years ago, it has caused a lot of devastations worldwide; especially in the developing countries. Globally, it is estimated that close to 40 million people are infected with HIV, with over $90 \%$ in developing countries and $64 \%$ in sub-Saharan Africa alone. ${ }^{[1]}$ Youth aged 10-24 years, comprise about one-fifth of the world's population and the HIV/AIDS pandemic has become a leading development challenge among them. Worldwide, people aged 15 to 24 years account for about $30 \%$ of all people living with HIV/AIDS. ${ }^{[2]}$ Half of all new HIV infections occur among youths, with about five young people becoming infected per minute. ${ }^{[3]}$

Nigeria, with a sero-prevalence rate of $4.1 \%$, is the third most affected country in the world as it has approximately 3.5 million infected people. ${ }^{[4]}$ Youths aged $15-24$ years, have one of the highest sero-prevalence rates, but this trend has been decreasing since 2001. At present, the prevalence among those aged 15-24 years is $4.2 \%$. Within this group, the prevalence among those $15-19$ years is $3 \%$ while that among those who are 20-24 years is $4.6 \%$. ${ }^{[4]}$

Although young people suffer most from HIV/AIDS, the epidemic among youths remains largely indiscernible ${ }^{[5]}$ Moreover, since young people are likely to have been recently infected; many are at the primary, most infectious stage, where behaviour change could be especially effective at reducing further HIV transmission. ${ }^{[6]}$ Voluntary Counselling and Testing (VCT) for HIV/AIDS, which is the gateway to HIV and AIDS prevention, care, treatment and support is a major intervention that can help to achieve this purpose. ${ }^{[7]}$ It provides accurate and timely information about HIV/AIDS and helps to identify those directly and indirectly affected by HIV in order to determine those who require care and treatment and encourage early and appropriate uptake of services. VCT helps to prevent HIV transmission and acquisition by promoting behaviour change. ${ }^{[8]}$ However, the uptake of VCT services is still very low ${ }^{[9,10]}$

Research indicates that even though there is a high level of awareness of existence of HIV/AIDS, there is a lower level of in-depth knowledge especially on modes of transmission and prevention. ${ }^{[11,12]}$ Similarly, even though awareness about VCT is increasing, accurate knowledge about it is much lower and there are still a lot of misconceptions ${ }^{[13,14,15]}$ While misconceptions about HIV transmission and prevention entrenches stigmatization and discourages preventive actions, misconceptions about VCT usually constitute barriers to its uptake. Already in low and middle income countries, only $10 \%$ of those who need VCT have access to it. ${ }^{[16]}$ 
Risky sexual behaviour that can predispose to HIV is high among youths in Nigerian universities. Corps members usually aged between 20-30 years and fresh graduates from higher institutions of learning, present a good picture of the youth in these institutions. ${ }^{[17]}$ They also represent diverse ethnic and cultural backgrounds that provided a rich mix of persons for the study. However, little is known about HIV and VCT knowledge and attitude among them. A study on their knowledge and attitude to HIV and VCT would reveal the knowledge and attitudinal gaps that still exist among them and also suggest the interventions that are necessary to close these gaps. These would help in reducing stigmatization against people living with HIV/AIDS (PLWHAs) and improving the uptake of VCT which is an important preventive action against the disease. Preventing HIV infection among young people would not just prevent the spread but reduce the mounting cost of treatment, providing resources that could help meet other needs of young people. ${ }^{[12]}$

This study was conducted to determine the knowledge and attitude to HIV and VCT among youth corps members in Ile-Ife and Ilesa, South Western Nigeria.

\section{Methods}

The study was conducted in Ile-Ife and Ilesa Local Government Areas (LGAs) of Osun State, one of the six states in the Southwest geo-political zone of Nigeria. The National Youth Service Corps (NYSC) members are usually posted yearly to all the states in the country in two batches (A \& B). They are usually between the ages of 20 and 30 years, mostly unmarried and represent different ethnic, socio-economic, cultural and religious groups in Nigeria. These new graduates first undergo a three-week orientation at the various NYSC orientation camps in the states, from where they are posted to institutions in all LGAs in the states. Osun State consists of thirty LGAs zoned into four NYSC Inspectorates

The study employed a descriptive cross-sectional design and the study population consisted of unmarried corps members posted to Ife and Ilesa LGAs of Osun State. Assuming a 95\% level of confidence, an estimate of VCT uptake of $17.8 \%$ and a maximum acceptable difference from true proportion of $5 \%$, the formula for estimating single proportions was used to obtain the minimum estimated sample size of $225 .{ }^{[17]} \mathrm{A}$ total of 330 participants were eventually interviewed.

Respondents were recruited into the study using multistage sampling technique. Osun State is divided into four NYSC Zonal Inspectorates each consisting of six or seven LGAs. Two of these, Ife and Ilesa Inspectorates, were selected by balloting. Out of the seven LGAs in Ife Inspectorate, Ife Central was chosen by simple balloting while Ilesa West was chosen in a similar manner out of the six LGAs in Ilesa Inspectorate. All the eligible corps members in these two LGAs, 330 in all, were recruited into the study.

A pre-tested, semi-structured, self-administered questionnaire was used to obtain data. The questionnaire elicited information on respondents' socio-demographic characteristics and their knowledge and attitude to HIV/AIDS and VCT.

In determining the level of knowledge of each respondent about HIV/AIDS, a twenty three point scale developed by the researcher was used. Each correct response was scored one mark while non response or wrong response was scored zero mark. Those who scored eleven points or less were considered as having poor knowledge; those who scored between twelve and seventeen points were considered as having fair knowledge, while those who scored between eighteen and twenty three points were considered as having good knowledge.

Knowledge of each respondent about VCT was determined using a five point scale also developed by the researcher. Each correct response was scored one mark while non response or wrong response was scored zero mark. Those who scored 0-1 points were considered as having poor knowledge; those who scored 2-3 points were considered as having fair knowledge, while those who scored 4-5 points were considered as having good knowledge.

In determining the attitude to VCT, five questions, each scored one point, were used. The maximum score obtainable was five points. The mean attitudinal score was 3.92. Respondents who scored below this were considered as having negative attitude to VCT; while those who scored above this were considered as having positive attitude to VCT.

Data were analyzed using the Statistical Package for Social Sciences version 15. Continuous data such as age were summarized as means. Discrete data were summarized as proportions and presented as frequency tables.

Ethical approval was obtained from the Ethical Committee of Obafemi Awolowo University Teaching Hospitals, Ile-Ife. Permission to carry out the study was obtained from the State Coordinator of the NYSC, Osun State and the respective NYSC Local Government Inspectors. Written consents were obtained from the respondents before being drafted into the study.

\section{Results}

A total of 307 out of 330 questionnaires were correctly filled and returned (response rate of 93\%) Two hundred and eighty five (92.8\%) respondents were in the 20-29 year old age group and the mean age was 26.04 
\pm 2.4 years. The males were almost as many as the females and $92.8 \%$ were Christians. Two hundred and twenty three $(72.6 \%)$ were of non Yoruba origin and $256(83.4 \%)$ were university graduates. One hundred and thirty three (43.3\%) studied Arts, Law and Social Sciences, 93 (30.3\%) studied pure, applied and health sciences while the rest studied others courses.

Table 1 shows knowledge of transmission and prevention of HIV among respondents. Majority $(97.4 \%)$ of the respondents knew that HIV can be transmitted through unprotected sexual intercourse and blood transfusion (88.6\%). Knowledge about transmission through deep kissing was lowest (53.1\%). Majority of the respondents knew that HIV can be prevented through sexual abstinence (85.0\%), consistent use of condom $(73.9 \%)$ and avoiding sharing of sharp objects $(70.7 \%)$. Knowledge about prevention through delaying sex till marriage was lowest $(38.8 \%)$.

Table 2 shows respondents' misconceptions about route of transmission and modes of prevention of HIV. Misconception about route of transmission was highest about sharing food with infected persons. (60.3\%) but was least about mosquito bites (35.5.0\%). Misconception about mode of prevention was highest about praying to God (73.6\%) but was lowest about seeking protection from a traditional healer $(49.2 \%)$.

Overall, 60 (19.5\%), $148(48.2 \%)$ and 99 (32.2\%) respondents had good, fair and poor knowledge of HIV respectively (Fig 1)

Table 3 shows respondents' knowledge and misconceptions about VCT. Two hundred and sixty six (86.6\%) respondents knew that VCT was information given about HIV/AIDS in addition to testing for the virus. Many of them however had the misconception that VCT was information given about family planning 220 $(71.7 \%)$ and about blood group and sickle cell disease $214(69.7 \%)$.

Overall, 63 (20.5\%), $156(50.8 \%)$ and 88 (28.7\%) had good, fair and poor knowledge of VCT respectively (Fig 2).

Table 4 shows the attitude to VCT among respondents. Sixty seven (21.8\%) respondents wrongly agreed that having VCT is like knowing one's day of death, $36(11.7 \%)$ felt that it creates anxiety and so should be avoided, while $16(5.2 \%)$ felt it is for those who are frequently sick.

Overall, $58.0 \%$ of the respondents had positive attitude to VCT while $42.0 \%$ had negative attitude to VCT (Fig 3)

Table 1: Respondents' knowledge about routes of transmission and modes of prevention of HIV

\begin{tabular}{ll}
\hline Routes of Transmission & $\mathbf{N = 3 0 7}$ \\
\hline Sexual intercourse & Freq (\%) \\
Blood transfusion & $299(97.4)$ \\
Sharing of sharp objects & $272(88.6)$ \\
Transmission from mother-to-child & $198(64.5)$ \\
Deep kissing & $191(62.2)$ \\
& $163(53.1)$ \\
\hline Modes of Prevention & Freq(\%) \\
Sexual abstinence & $261(85.0)$ \\
Using condom every time & $227(73.9)$ \\
Avoiding sharing sharp objects & $217(70.7)$ \\
Avoiding sex with people with multiple partners & $196(63.8)$ \\
Being faithful to one uninfected partner & $185(60.3)$ \\
Avoiding sex with sex workers & $176(57.3)$ \\
Reducing number of sex partners & $174(56.7)$ \\
Delaying sexual intercourse till marriage & $119(38.8)$ \\
\hline
\end{tabular}

Table 2: Respondents' misconceptions about routes of transmission and modes of prevention of HIV

\begin{tabular}{ll}
\hline Routes of transmission & $\mathbf{N}=\mathbf{3 0 7}$ \\
Sharing food with infected person & Freq (\%) \\
Through witchcraft & $185(60.3)$ \\
Sharing toilets & $144(46.9)$ \\
Sharing same bed & $135(44.0)$ \\
Hugging & $131(42.7)$ \\
Mosquito bites & $125(40.7)$ \\
\hline Modes of prevention & $109(35.5)$ \\
Praying to God & Freq (\%) \\
Going for check ups & $226(73.6)$ \\
Using antibiotics & $217(70.7)$ \\
Seeking protection from a traditional & $156(50.8)$ \\
healer & $151(49.2)$ \\
\hline
\end{tabular}




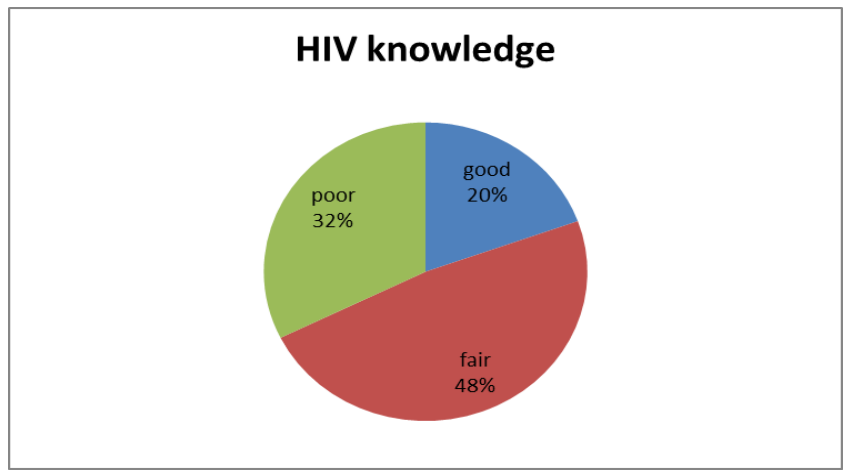

Figure 1: Respondents' knowledge of HIV

Table 4: Knowledge and misconceptions about voluntary counselling and testing among respondents

\begin{tabular}{ll}
\hline Knowledge about Voluntary Counselling and Testing & $\mathbf{N = 3 0 7}$ \\
\hline & Freq (\%) \\
Is information given about HIV in addition to testing for the virus & $266(86.6)$ \\
Consists of pre-test counselling & $171(55.7)$ \\
Consists of post- test counselling & $161(52.4)$ \\
\hline Misconceptions about Voluntary Counselling and Testing & $220(71.7)$ \\
VCT is information given about family planning & $214(69.7)$ \\
VCT is information given about blood group and sickle cell disease & \\
\hline
\end{tabular}

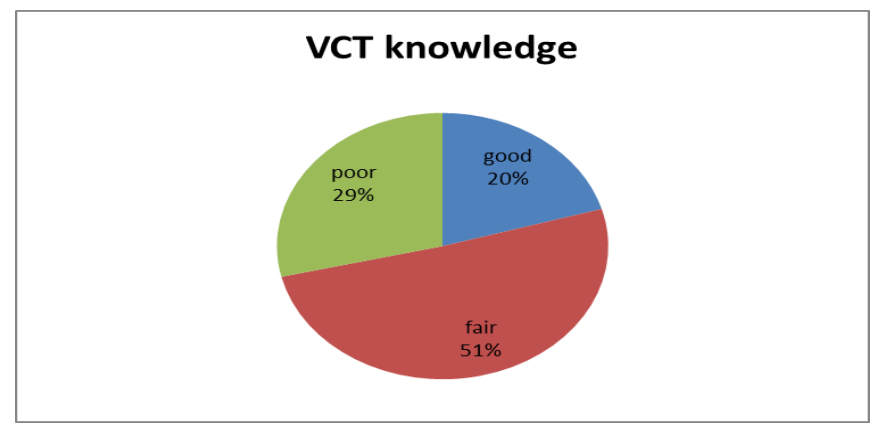

Figure 2: Respondents' knowledge of voluntary counselling and testing

Table 5: Attitude of respondents to voluntary counselling and testing

\begin{tabular}{|c|c|c|}
\hline Attitude & Response & Freq $(\%)$ \\
\hline \multirow[t]{3}{*}{ VCT can encourage safer sex } & Agree & $275(89.6)$ \\
\hline & Disagree & $17(6.1)$ \\
\hline & Undecided & $13(4.2)$ \\
\hline \multirow[t]{3}{*}{ VCT gives access to early treatment } & Agree & $272(88.6)$ \\
\hline & Disagree & $17(5.5)$ \\
\hline & Undecided & $18(5.9)$ \\
\hline Having VCT is like knowing one's & Agree & $67(21.8)$ \\
\hline \multirow[t]{2}{*}{ day of death } & Disagree & $199(64.8)$ \\
\hline & Undecided & $41(13.4)$ \\
\hline \multirow[t]{3}{*}{ VCT creates anxiety and should be avoided } & Agree & $36(11.7)$ \\
\hline & Disagree & $217(70.7)$ \\
\hline & Undecided & $54(17.6)$ \\
\hline \multirow[t]{3}{*}{ VCT is for those who are frequently sick } & Agree & $16(5.2)$ \\
\hline & Disagree & $265(86.3)$ \\
\hline & Undecided & $26(8.5)$ \\
\hline
\end{tabular}




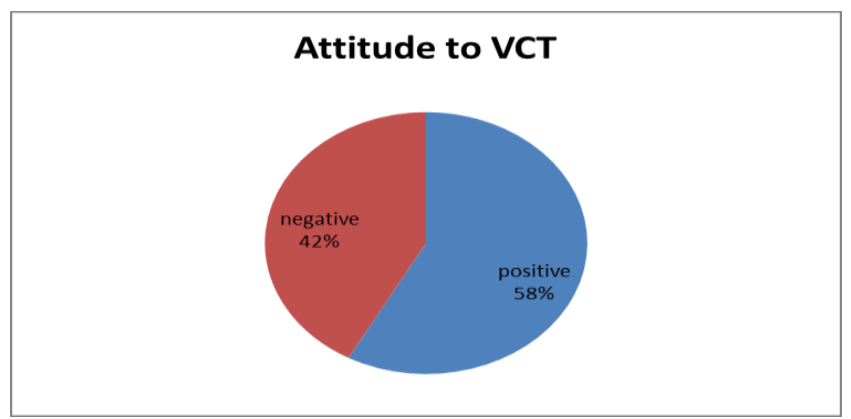

Figure 3:Respondents' attitude to voluntary counselling and testing

\section{Discussion}

The study examined knowledge and attitude to HIV and VCT among corps members in Ilesa and IleIfe, Nigeria. Majority of the respondents knew that HIV could be transmitted through unprotected sexual intercourse, blood transfusion and sharing of sharp objects. The least mentioned route of transmission was deep kissing. Majority of the respondents also knew that HIV could be prevented through sexual abstinence, consistent use of condom and avoiding sharing of sharp objects. This is consistent with the reports of various other studies conducted within and outside the country ${ }^{[11,18]}$

There were however several misconceptions about HIV transmission and prevention among the respondents. Many of them felt that the virus could be transmitted through sharing food, toilet and bed with an infected person; and through witchcraft and hugging. The misconceptions about HIV prevention included going for check up, praying to God, use of antibiotics and seeking help from traditional healers. Rejecting major misconceptions about modes of HIV transmission is as important as correct knowledge of true modes of transmission; likewise for prevention. Misconceptions about HIV transmission weaken the motivation to adopt safer sexual behaviour and strengthen stigmatization against people living with the virus. Misconceptions about HIV prevention give people false confidence about protection against HIV, while actually predisposing them to the infection. It therefore prevents them from making informed choices and taking appropriate action. ${ }^{[19,18,20]}$

Similar misconceptions about HIV transmission and prevention were reported by studies conducted in Uganda, Botswana, Nigeria, South West China and Cyprus. ${ }^{[11,19,21,22,23]}$ Overall, only about a fifth of the respondents had good knowledge of HIV; about half had fair knowledge while the remaining one-third had poor knowledge of HIV. The high level of misconceptions about HIV noted in this study was responsible for most of the respondents having low overall knowledge score.

Majority of the respondents had the correct knowledge that VCT gives information and counselling about HIV in addition to testing for the virus. However, only about half of them knew that VCT consists of pretest and post-test counselling. Well over half of the respondents however had the misconception that VCT is information given about blood group and sickle cell disease and information about family planning.

The respondents probably thought that VCT is just like other blood tests done in health care facilities which might be responsible for their not knowing that pre and post test counselling are involved. The link between VCT and reproductive health services might probably be responsible for people's thought that it is related to family planning. It has actually been advocated that VCT should be linked with family planning and other reproductive health services in order to make it more accessible and acceptable to people.

On the whole, only a fifth of the respondents had good knowledge of VCT while the majority had fair knowledge. This finding is slightly lower than that of a study conducted among youths aged 15-24 years in Plateau, Nigeria in which $41.0 \%$ of the respondents had good knowledge of VCT. ${ }^{[24]}$ It however contrasts with the results of some studies conducted among Ugandan and Ethiopian youth in which majority of them had good knowledge about HCT. ${ }^{[14,25]}$ The disparity in the results can be due to differences in promotion and availability of VCT services in these countries. It can also be due to more respondents in this study having misconceptions about VCT services, thereby reducing their overall knowledge score since both accurate knowledge and misconceptions about VCT were considered.

Attitude towards a behavior is determined by the main beliefs about that behavior (behavioural beliefs). Each belief links the behavior to a certain outcome or cost incurred by carrying out the behavior. The person's attitude towards the behavior is determined by the person's assessment of the outcome associated with the behavior and by the strength of these associations. A person who believes that performing a given behavior will lead to mostly positive outcomes will hold a favourable attitude to performing the action whereas a person who believes that performing the action will lead to mostly negative outcomes will hold an unfavourable attitude to performing the action. ${ }^{[26]}$

Majority of the respondents believed that VCT can encourage safer sex and also help HIV positive people access treatment on time which represent positive attitude. Some of them wrongly believed that having 
VCT is like knowing one's day of death; that it creates anxiety and so should be avoided; and that VCT is for those who are frequently sick. These are negative attitudes. Attitude predicts intentions, which in turn predicts behavior. Those who have positive attitude to VCT are more likely to access the services and recommend it for others.

Overall, $58.0 \%$ of the respondents in this study had positive attitude to VCT while the remaining $42.0 \%$ had negative attitude to it. This finding is higher than that reported in a study among youths in Plateau State, Nigeria in which $40.0 \%$ of the respondents had positive attitude to VCT while it is lower than those reported among youths in Uganda and Ethiopia in which $83.7 \%$ and $73 \%$ of the respondents had positive attitude to VCT. ${ }^{[14,24,25]}$ On the other hand, a Ghanaian study conducted among university students reported a negative attitude to VCT. ${ }^{[13]}$ The differences in attitude to VCT detected in these studies might be due to differences in the respondents' knowledge, misconceptions and perceptions about VCT and in the questions used to elicit attitude in these studies.

The policy implication of this study for health planners and policy makers is that HIV and VCT education among university students should be intensified. This should be targeted at correcting the prevailing misconceptions about HIV and VCT among them while at the same time reinforcing their knowledge.

Further studies are necessary to investigate the factors that affect corps members' attitude to VCT so as to inform the interventions that are necessary to change their attitude.

\section{Conclusion}

The study concluded that corps members in Ilesa and Ife, Southwest Nigeria had a fair knowledge of HIV, a fair knowledge of VCT and a positive attitude to VCT. Educational programs on HIV and VCT should be intensified especially to address the misconceptions noted among them.

\section{Acknowledgement}

The authors would like to acknowledge the members of the National Youth Service Corps who were interviewed.

\section{References}

[1]. Joint United Nations Programme on HIV/AIDS (UNAIDS), Fact sheets: United Nations special session on HIV/AIDS: global crisis-global action, (New York: United Nations Department of Public Information and UNAIDS, 2001) 41

[2]. Joint United Nations Programme on HIV/AIDS (UNAIDS) and World Health Organization (WHO), AIDS epidemic update. (Geneva: UNAIDS, WHO, 2001) 1-2

[3]. Joint United Nations Programme on HIV/AIDS (UNAIDS), Listen, learn, live: world AIDS campaign with children and young people, facts and figures, (Geneva: UNAIDS, 1999) 4

Available from: URL: http://www.unaids.org/wac/1999/eng/facts-e.pdf, accessed $10^{\text {th }}$ June 2009

[4]. National Agency for the Control of AIDS. Global AIDS response: country progress report Nigeria 2012. (Abuja Nigeria, NACA, 2012)

[5]. G. Macdonald, R. O’Brien, K. Pittman, M. Kimball, Adolescents and HIV disease: defining the problem and its prevention, (Washington DC: Academy for Educational Development, 1994) 56

[6]. R. Royce, A. Seña, W. Cates, M. Cohen, Sexual transmission of HIV. The New England Journal of Medicine, 336(15), 1997, 10721078

[7]. Chadborn TR, McGarrigle CA, Waight PA, Fenton K. On behalf of the HIV testing surveillance collaborative group. Sexually Transmitted Infections, 80, 2004, 145-150.

[8]. World Health Organization, Rapid HIV tests: guidelines for use in HIV testing and counselling services in resource-constrained settings, (Geneva: World Health Organization, 2004)

[9]. K.T. Ijadunola, T.C. Abiona, O.O. Odu, M.Y. Ijadunola, College students in Nigeria underestimate their risk of contracting HIV/AIDS infection, European Journal of Contraception and Reproductive Health Care, 12(2), 2007, $131-137$.

[10]. Federal Ministry of Education,. National survey on HIV/AIDS knowledge, attitudes, practices, skills and school health in Nigeria. (Abuja: Federal Ministry of Education, 2006)

[11]. Federal Ministry of Health, 2005 National HIV/AIDS and reproductive health survey, (Abuja: Federal Ministry of Health, 2006).

[12]. NACP/GHS, 2006 Behavioural surveillance survey-Adults. Quarterly Technical Bulletin on HIV/AIDS-STIs in Ghana, 17(4), 2010, $1-12$.

[13]. E.S. Donkor, Knowledge, attitudes and practices of voluntary counselling and testing for HIV among university students, Global Advanced Research Journal of Social Science, 1(2) 2012, 041-046. 2012. Available at http://garj.org/garjss/index.htm

[14]. Z. Addis, Y. Aregawi, S. Yitayal, A. Abebe, B. Wubet and M. Biniam et al, Knowledge, attitude and practice towards voluntary counseling and testing among university students in North West Ethiopia: a cross sectional study. BMC Public Health, 13, 2013, 714 http://www.biomedcentral.com/1471-2458/13/714

[15]. E. O. Amu and K.T. Ijadunola, Awareness and knowledge of HIV counselling and testing among adults of reproductive age in Osun State Nigeria. Trends in Medical Research, 6, 2011, 265-272.

[16]. Joint United Nations Programme on HIV/AIDS (UNAIDS), AIDS epidemic update. (Geneva: UNAIDS, 2004)Available from: http://www.unaids.org. accessed $11^{\text {th }}$ May 2009.

[17]. National Population Commission, 2003 Nigeria Demographic and Health Survey, (MD USA: NPC and ORC Macro Calverton, 2004) Available from: http://www.measuredhs.com/pubs/pdf/GF5/nigeria 2003 generalfactsheet.pdf

[18]. H.Z. Qian, N. Wang, S. Dong, H. Chen, Y. Zhang, E. Chamot et al, Association of misconceptions about HIV transmission and discriminatory attitudes in rural China, AIDS Care, 19(10), 2007) 1283-1287. doi:10.1080/09540120701402814.

[19]. G. Letamo, Misconceptions about HIV prevention and transmission in Botswana, African Journal of AIDS Research, 6(2), 2007, 193-198 
[20]. Joint United Nations Programme on HIV/AIDS (UNAIDS), 2012 Global AIDS Response Progress (Geneva: UNAIDS, 2013) 24-25

[21]. A.M. Muganga, M.E. Bahemuka, C.O. Ariono, R.B. Denis, Knowledge and acceptability of HIV voluntary counselling and testing among Ugandan urban youth, Proc. Conf. on AIDS, 2002, 14

[22]. V.J. Derlega, X. Yang, H. Luo, Misconceptions about HIV transmission, stigma and willingness to take sexual risks in South Western China, International Journal of Sexually Transmitted Diseases and AIDS, 17(6), 2006, 406-409.

[23]. C. Cleanthous, E. Galati, N. Kalogirou, A. Christodoulou, and M. Basho, Cyprus university students' knowledge of HIV-AIDS: a little knowledge is a dangerous weapon. Sexologies, Suppl 1:150, 2008

[24]. M. Abubakar, Impact of health campaign on knowledge, attitude and practice of VCT among young people in Dengi community, Plateau State, master's diss. Obafemi Awolowo University, Ile-Ife, Nigeria, 2008.

[25]. D.L. Kitara, C. Amone, C. Okello. Knowledge and misconceptions about HIV counseling and testing (HCT) among the postconflict youths of Gulu, Northern Uganda: a prospective study design. Pan African Medical Journal. 12:31, 2012; Available at: http://www.panafrican-med-journal.com/content/article/12/31/full/

[26]. I. Ajzen, From intentions to actions in: Attitude, personality and behaviour. (Chicago: The Dorsey Press, 1988) 112-145.

\section{CONFLICT OF INTEREST}

$\mathrm{We}$, the authors declare that there is no conflict of interest that might bias our work or inappropriately influence our judgment 